\title{
A win-win proposition: help us to build better evidence-based information systems for you
}

As readers of Evidence-Based Medicine (EBM), you may be interested in some of the developments currently underway to enhance the match between healthcare research reports and your own practice information needs. EBM uses validity and relevance checks to identify the best evidence for clinical practice from over 100 journals, but we realise that the range of topics is broader than most clinicians are interested in. Furthermore, our relevance assessments in the past have been based on the views of a combination of general practitioners, specialists and general internists, working at either the primary or referred care level. This may or may not represent your own interests well-we think we can do better, with a little help from you.

Recently, we have developed an online rating system that allows us to poll many more doctors as "Sentinel Readers" to determine the level of interest in a given article from the individual perspectives of doctors in primary care, hospitalbased general internal medicine, and relevant subspecialties of internal medicine. This system is now being used to assess the practical relevance of articles that meet our criteria for scientific merit and is being employed to help select content featured in ACP Journal Club and EBM and soon to inform authors of PIER, the new Physicians' Information and Education Resource of the American College of Physicians. Our primary objective is to help doctors keep up to date with information that they believe is truly relevant to the care of their own patients.

Those who participate as Sentinel Readers can specify the type and rate of articles that are sent their way, and enjoy many benefits from the process. In addition to seeing critically appraised articles "hot off the press," readers can compare their ratings and comments with those of other readers, both in their own discipline and others. Readers are provided with regularly updated listings of "Stellar Articles," articles that were most highly rated in the previous week. North American readers enjoy a choice of Continuing Education credit options and credits are automatically tracked and provided annually in summary form. EBM will be a better, more relevant resource as a result, and new alerting and lookup opportunities are under development.

Currently, over 800 Sentinel Readers are enrolled worldwide in the rating system and we will continue to recruit until we reach a state in which each reader is perfectly comfortable with the rate at which articles are sent their way. At present, we estimate we will reach that state with about 1500 readers.

We would like you to join us if you have the following qualifications:

formal training fully completed in a primary care medical discipline (eg, general practice, family practice, or internal medicine), hospital- or referral-based general internal medicine, or subspecialty of internal medicine (eg, cardiology, oncology, or neurology) in at least part-time clinical practice with reliable internet access able to quickly respond to e-mail requests for rating articles (rating an article takes about 10 minutes).

Please see our advertisement in this issue for more information on this project or e-mail us at plus@mcmaster.ca.

BRIAN HAYNES, MD, PhD PAUL GLASZIOU, MD, PhD

Editors

\section{Journals reviewed for this issue*}

Acta Obstet Gynecol Scand
Age Ageing
Am J Cardiol
Am J Med
Am J Obstet Gynecol
Am J Psychiatry
Am J Public Health
Am J Respir Crit Care Med
Ann Emerg Med
Ann Intern Med
Ann Surg
Arch Dis Child
Arch Gen Psychiatry
Arch Intern Med
Arch Neurol

Arch Pediatr Adolesc Med
Arch Surg
Arthritis Rheum
BJOG
BMJ
BrJ Gen Pract
BrJ Psychiatry
BrJ Surg
CMAJ
Chest
Circulation
Cochrane Library
Crit Care Med
Diabetes Care
Gastroenterology

*Approximately 60 additional journals are reviewed. This list is available on request. 